\title{
Uso do Software HagaQuê como apoio na produção textual aos alunos com déficit cognitivo
} Use of the Hagache software as a support in textual production to students with cognitive
deficit

\author{
Maria Selma Cavalcante de Sousa \\ Universidade Estadual de Roraima, Roraima, Brasil \\ selmacaval@gmail.com \\ Lourena Sousa dos Santos \\ Universidade Estadual de Roraima, Roraima, Brasil \\ santoslourena@gmail.com \\ Lucas Sousa dos Santos \\ Universidade Federal de Roraima, Roraima, Brasil \\ Lucaslorival2@gmail.com
}

Fecha recepción: 27/04/2020

Páginas 69-83

Fecha aceptación: 29/05/2020

\section{Resumo.}

Esta pesquisa resulta da observação realizada na sala de recursos do Centro de Atendimento Especializado Boa Vista / RR com alunos com Déficit Cognitivo atendidos na sala de recursos multifuncionais do Centro de Atendimento Especializado Boa Vista / RR. Com este trabalho, pretendemos apresentar reflexões sobre 0 uso de softwares educacionais voltados para a produção de texto HagáQuê com alunos com com prometimento cognitivo. $O$ trabalho esta dividido pela introdução, define o problema, os objetivos e a estrutura do trabalho. Na sequência, apresentamos os fundamentos teóricos, que são a revisão da literatura. Na metodologia da pesquisa, optamos por um modelo qualitativa e descritiva. Como instrumento de coleta de dados, foi elaborada e apresentada na análise dos resultados uma lista de observação com critérios e indicadores. Após a análise, concluímos que os resultados obtidos responde à questão principal da pesquisa: como o software HagáQuê pode ser considerado uma ferramenta de apoio à leitura e produção de gibis para alunos com déficits cognitivo. Portanto, a presente investigação conclui que os resultados foram bastante satisfatórios, mesmo entendendo que obstáculos, como a dificuldade decorrente do déficit cognitivo dos alunos, são um obstáculo para a obtenção de um aprendizado completo, porém, ficou claro na pesquisa que os alunos podem ler e produzir textos em quadrinhos usando o software HagáQuê.

Palavras chave: software hagáquê, cognitive déficit, textual production 


\begin{abstract}
.
This research results from the observation made in the resource room of the Specialized Care Center Boa Vista / RR with students with Cognitive Deficit attended in the multifunctional resource room of the Specialized Care Center Boa Vista / RR. With this work, we intend to present reflections on the use of educational software aimed at the production of HagáQuê text with students with cognitive promise. The work is divided by the introduction, it defines the problem, the objectives and the structure of the work. Next, we present the theoretical foundations, which are the literature review. In the research methodology, we opted for a qualitative and descriptive model. As an instrument for data collection, an observation list with criteria and indicators was developed and presented in the analysis of the results. After the analysis, we conclude that the results obtained answer the main question of the research: how the HagáQuê software can be considered a tool to support the reading and production of comics for students with cognitive deficits. Therefore, the present investigation concludes that the results were quite satisfactory, even understanding that obstacles, such as the difficulty resulting from the students' cognitive deficit, are an obstacle to obtain a complete learning, however, it was clear in the research that students can read and produce comic texts using the HagáQuê software.
\end{abstract}

Keywords: software hagáquê, cognitive deficit, textual production

\title{
1.-Introdução.
}

Atualmente a Educação Especial é entendida como a modalidade de ensino que tem como objetivo quebrar as barreiras que impedem a criança de exercer a sua cidadania. É preciso ficar claro que o atendimento educacional especializado deve ser encarado como um complemento ou suplemento da escolarização e não seu substituto. Receber no Centro de Atendimento Especializado um aluno com déficit cognitivo é uma tarefa bem complexa, requer que 0 professor perceba quais são as dificuldades que 0 aluno enfrentará para aprender, assim, dessa forma poderá encontrar estratégias para ensinar. Segundo Rodrigues (2009, p.92) os alunos com esse tipo de deficiência possuem baixa concentração, dificuldade de comunicação e menor capacidade para compreender a escrita, por isso necessitam de um sistema de aprendizado diferente. Na procura de metodologias que auxiliem na superação destes obstáculos a tecnologia pode se apresentar como uma grande aliada para motivar 0 aluno. Quem tem déficit intelectual precisa de espaço bem organizado, rotina, atividades lógicas e regras. A sala de aula comum e seus diversos elementos dificultam estes indivíduos focarem seu raciocínio. 0 professor deve ser capaz de encontrar estratégias que mantenham o aluno atento. Diante desses pressupostos, busca com essa pesquisa analisar o software livre HagáQuê como ferramenta de apoio a leitura e produção de textos em quadrinho com alunos com déficit cognitivo atendidos na sala de recursos multifuncionais do Centro de Atendimento Especializado de Boa Vista/RR, refletindo sobre como o software livre HagáQuê pode ser considerada uma ferramenta de apoio a leitura e produção textual em quadrinho para os alunos com déficit cognitivo. 


\section{2.-0 software educativo hagáquê.}

Entende-se por Software educativo, o aplicativo criado com a intenção de editar palavras, tendo como objetivo produzir textos, correspondências, relatórios, histórias em quadrinhos, etc. Segundo Lucena, (2010) este tipo de software caracteriza-se como [...] todo aquele que possa ser usado para algum objetivo educacional, pedagogicamente defensável, por professores e, qualquer que seja a natureza ou finalidade para a qual tenha sido criado.

Atualmente, já se pode afirmar que os indivíduos com déficit intelectual são capazes de realizar processos cognitivos semelhantes aos das crianças que não apresentam esse tipo de déficit, no que se refere ao aprendizado da leitura e da escrita, embora seu ritmo de aprendizagem aconteça de forma mais lenta. Por isso, as estratégias de ensino para esses podem ser as mesmas utilizadas com os demais.

0 uso de software educativo pode vir a facilitar a aprendizagem das pessoas com necessidades educativas especiais. Enfatiza-se ainda que no ensino da escrita seja preciso estimular 0 aluno a se comportar de forma ativa na atribuição de significados para aquilo que se aprende. Para tanto, é preciso que ocorra uma reflexão sobre a maneira pela qual pode ocorrer o encontro da tecnologia com o ensino de língua, respaldado numa teoria consistente capaz de se propor a resolver problemas no processamento textual comum entre os com déficit cognitivo.

De acordo com Vygotsky, (1991) com a abertura nas zonas de desenvolvimento proximal (que é a distância entre aquilo que a criança faz sozinha e o que ela é capaz de fazer a intervenção de um adulto), ocorre à potencialidade para aprender (que difere de indivíduo para indivíduo), nas quais, as interações sociais são fundamentais(p. 31). Ainda segundo ao autor, a atividade do sujeito refere-se ao domínio dos instrumentos de mediação. É necessária uma observação precisa por parte do professor na compreensão da zona proximal de Vygotsky, de forma que consiga orientar o aprendizado do aluno no sentido de adiantar 0 desenvolvimento potencial dele quando repassar o ensino do grupo para 0 indivíduo. Como o desenvolvimento mental só pode se realizar por intermédio do aprendizado, conclui-se que, se o ambiente também influencia a internalização das atividades cognitivas no indivíduo, já que o aprendizado gera o desenvolvimento.

Neste sentido, a busca por novas metodologias e recursos que permitam despertar no aluno o interesse por manusear o novo, pode encontrar na utilização de novas tecnologias uma forma de fortalecer a aprendizagem do aluno para a produção de textos.

Paulo Freire (2002) fala sobre a mudança que o computador provocou na maneira de os indivíduos se relacionarem com a leitura e a escrita. Chama a atenção para o aspecto da ludicidade como possibilidade de trabalho pedagógico utilizando o software educacional, entre os quais cita os editores de histórias em quadrinhos. Desta forma, o autor pontua que os recursos tecnológicos permitem ao indivíduo colocar a sua linguagem em funcionamento, de mudar as condições de produção do texto, de praticar a reescrita, mostrando que "aprender a escrever significa escolher entre possibilidades, tomar diferentes decisões" ( $p$. 310).

O autor Gesueli, (2004), enfatiza que: Na produção escrita, a imagem é garantia do significado a qual representa, muitas vezes, todo um enunciado [...] a possibilidade de a imagem fazer parte da produção textual do aluno, dada a experiência visual a que está imbricado, sem que necessariamente esta imagem deva ser substituída por palavras escritas (p.47). 
O Software Livre HagáQuê é considerado educativo, destinado primariamente a ser utilizado como um instrumento auxiliar no processo de leitura e produção de texto através da linguagem escrita. Trata-se de um editor de histórias em quadrinhos que possui um banco de imagens com diversos componentes para a criação de uma história em quadrinhos com cenários, personagens e balões, além de vários recursos de edição de figuras. 0 som é um recurso a mais oferecido para enriquecer a História em Quadrinhos criada no computador. Através dele espera-se despertar no aluno o interesse de criar histórias para os personagens, assim também, como aprimorar a leitura.

Ele apresenta um conjunto de ferramentas comuns a outros editores de desenho como: aumentar e diminuir figuras, selecionar, apagar, pintar etc. Dispõe, ainda, de um menu com opções relacionadas à edição da história de modo geral. Várias opções podem ser acionadas com o clique do botão direito do mouse, contemplando aqueles usuários mais familiarizados com programas na plataforma Windows.

Para melhor comodidade na produção, 0 aluno tem varias opções para enriquecimento visual do seu texto, o Software apresenta uma gama de imagens e personagens, cenários e objetos, tanto colorido quanto em preto e branco (e que podem ser coloridos no próprio software). Possui, também, imagens de balões e onomatopeias.

É possível, ainda, inserir novas imagens - capturadas na Internet, por exemplo no banco de imagens inicial do HagáQuê, tornando-as disponíveis a qualquer outro usuário do software, sem necessidade de procurar as figuras pelos nomes dos arquivos. Essas figuras podem ser alteradas por meio das ferramentas do software: aumentar e diminuir o tamanho; girar e inverter, modificando posições e direções; tornando-se desnecessário o uso associado de um editor de imagens. O Software Livre HagáQuê permite a inclusão de som gravado por meio de microfone ligado ao computador ou de arquivos de outros programas no formato WAV. Quanto ao texto no Software HagáQuê, ele é sempre escrito com uma mesma fonte e a criança pode escolher seu tamanho. Há três opções de tamanho de fonte: pequena, média e grande.

A construção do texto está relacionado com os objetivos aos quais foram determinados para a aula com o uso do software HagáQuê. As imagens e ferramentas de manuseio disponibilizado no Software Livre apenas ajudam na percepção do aluno acerca de sua criatividade.

Acompanhar e analisar a partir da observação, o uso do Software HagáQuê com alunos que apresentam Déficit Cognitivo no Centro de Atendimento a Pessoa com Deficiência/BV, foi uma forma de contribuir com o sucesso da inclusão e com o desenvolvimento desses alunos.

\section{3.-Deficit Cognitivo.}

A deficiência vem sendo caracterizada ao longo do tempo conforme o momento histórico, cultural e social no qual é definida. (Monte \& Santos, 2004, p. 9). Isso fica comprovado através da forma com que ao longo da história a sociedade reagia diante do indivíduo que apresenta alguma deficiência ou algum tipo de anormalidade, mas o ponto comum é que 0 preconceito e a discriminação sempre os marcaram. Afogava-se, na Roma Antiga, crianças com deficiências, na Grécia, estas crianças eram sacrificadas ou as escondidas, tais atitudes se tornaram já parte da cultura desses povos. 
Na Idade Média, atribuía-se ao demônio as atitudes dos deficientes mentais, ou então, considerava-se que fosse uma forma de expiação dos pecados, ou ainda eram considerados como possuidores de poderes extraordinários ou, simplesmente fadados a serem motivo de distração para as pessoas que não apresentavam nenhum tipo de deficiência. Segundo Raiça (2006), neste período da história "as crianças indesejáveis ficavam a cargo da caridade cristã". Posteriormente, segundo a autora, devido ao avanço da ciência positivista a solução para estes casos era os sanatórios e hospitais gerais, depois tais pessoas "se tornaram objeto de estudo e passaram a ser acolhidas também em instituições especializadas" ( p. 15).

A educação destas pessoas surgiu, segundo Monte \& Santos (2004) com caráter assistencialista e terapêutico gerado pela preocupação de religiosos e filantropos europeus. Nos Estados Unidos e Canadá surgiram os primeiros programas sociais voltados para essa parcela da população, a França tomou as primeiras iniciativas para a educação de deficientes, em particular os deficientes auditivos, sendo criado do Método de Sinais (p. 9). Em 1784, foi fundado o Instituto Real dos Jovens Cegos e, mais tarde, Louis Braille criou 0 sistema Braille. Quanto aos deficientes mentais, as primeiras iniciativas para sua educação foram do médico francês Jean Marc Itard (sec. XIX) que sistematizou um método de ensino inspirado na experiência de Ayeron (o menino selvagem do sul da França) que consistia na repetição de experiências positivas. De acordo com Monte \& Santos (2004), foi em 1854 que no Brasil, implantou-se a educação para deficientes cegos e surdos (p. 10).

No início do século XX as escolas especiais difundiram-se pela Europa e Estados Unidos. Voltavam-se para o enfoque clínico e difundia-se o nome da médica Maria Montessori criadora do método de ensino direcionado para as crianças com deficiência mental. Seu método fundamenta-se na estimulação sensório-perceptiva e auto aprendizagem, utiliza jogos educativos e material concreto e ainda hoje é muito utilizado pela educação infantil também com as crianças sem nenhuma deficiência.

Os avanços científicos relacionados às causas das deficiências ocorridos ao longo dos tempos não eliminaram o preconceito as pessoas com necessidades especiais. Entretanto, conforme Monte \& Santos (2004) pode-se afirmar que a idade contemporânea é marcada pelo paradigma da cientificidade, do psicologismo, da valorização dos testes quantitativos, do treinamento sensorial e motor ( p. 10).

O que contribuiu para a criação de serviços especializados em educação especial e classes especiais foi a Declaração dos Direitos Humanos (1948) que garante o acesso de todos à educação, fazendo com que surgisse uma política nacional voltada para pessoas com necessidades educativas especiais.

Os Parâmetros Curriculares para Educação Especial (1998) dizem que o "déficit intelectual caracteriza-se por registrar um funcionamento do intelecto abaixo da média, associado ou não a algumas áreas de conduta ou da capacidade do indivíduo em comunicar-se, em observar os cuidados pessoais, ao seu desempenho na família e na comunidade, à independência na locomoção, saúde e segurança, no desempenho escolar, no lazer e no trabalho. Ou seja, nesse sentido, a déficit cognitivo caracteriza limitações que dizem respeito, especificamente, às funções cognitivas" (p. 16).

Segundo Paulon (2005) tal definição baseia-se na proposta pela American Association of Mental Retardation (AAMR) que tem servido como referência quanto ao entendimento, definição e classificação das condições desse déficit. Segundo a AAMR: "A deficiência mental é a incapacidade caracterizada por limitações significativas tanto no funcionamento 
intelectual quanto no comportamento adaptativo expresso em habilidades conceituais, sociais e práticas".( p. 11).

A Política Nacional de Educação Especial na Perspectiva da Educação Inclusiva (2008) tem como objetivo assegurar a inclusão escolar de alunos com déficit cognitivo, assim como as demais deficiências e transtornos, garantindo acesso e permanência desses alunos no ensino comum, com garantia de participação, aprendizagem e continuidade nos níveis mais elevados do ensino; transversalidade da modalidade de educação especial desde a educação infantil até a educação superior.

Vygotsky (1986) afirma que "uma criança com deficiência mental não é simplesmente menos desenvolvida que outra da sua idade, mas é uma criança que se desenvolve de outro modo"(p. 46). Para ele, as funções psicológicas superiores, que são características do ser humano, estão ancoradas, por um lado, nas características biológicas da espécie humana e, por outro, são desenvolvidas ao longo de sua história social.

$O$ autor afirma ainda que: A deficiência não deve ser concebida como um aspecto simplesmente orgânico, como um defeito. É preciso que as crianças com deficiência perpassem por restrições contundentes no campo social para que se desenvolvam. Ou seja, as particularidades psicológicas da criança com deficiência tem a base não só no núcleo biológico, e sim no social Assim, não existe uma única forma de aprender e tampouco uma única forma de ensinar, mas o "bom aprendizado" é, para Vygotsky (1986), aquele que envolve sempre a interação com outros indivíduos e a interferência direta ou indireta deles, e, fundamentalmente, o respeito ao modo peculiar de cada um aprender. A concepção interacionista se apoia na ideia de interação entre organismo e meio e vê a aquisição do conhecimento como um processo construído pela pessoa durante toda a sua vida, não estando pronto ao nascer nem sendo adquirido passivamente pelo meio.

Desta forma, é possível afirmar que o acesso da tecnologia possibilita um novo modo de comodidade para a inclusão digital, o aluno que apresenta déficit cognitivo apresenta grande interesse pela tecnologia, por isso a utilização do software livre HagáQuê no processo ensino aprendizagem é ideal para a situação pedagógica que tem por objetivo 0 incentivo para a leitura e produção textual através de quadrinhos, essa prática educativa funciona como um regulador externo da aprendizagem, concentrando o aluno na atividade que são desafiados.

Ao realizar os atendimento com os com Déficit cognitivo, foi possível constatar que os tem tempo e ritmo próprio de aprender, cada um se diferencia pelo jeito próprio de lidar com 0 saber, o motivo dessa observância envolve a busca de solução imediata para adaptar ou, seja, acomodar 0 aluno ao objeto, que nessa situação pedagógica o nosso objeto é 0 software livre HagáQuê, ferramenta tecnológica que agrega vários itens dinâmicos despertando no aluno com déficit cognitivo a vontade de ler e produzir textos.

\section{4.-Metodologia.}

0 trabalho em questão, apresenta como principal objetivo, analisar o software livre HagáQuê como ferramenta didática pedagógico para leitura e produção de textos em quadrinho com déficit cognitivo atendidos na sala de recursos multifuncionais do Centro de Atendimento Especializado de Boa Vista/RR e por se tratar apenas de uma observação na qual a investigadora não irá manipular as variáveis, trata-se de uma pesquisa de cunho nãoexperimental. Sampieri (et. Al 2006) "A pesquisa não experimental é uma pesquisa 
sistemática e empírica na qual as variáveis independentes não são manipuladas porque já ocorreram. As inferências sobre as relações entre variáveis se realizam sem intervenção ou influência direta, e essas relações são observadas tal como se deram em seu contexto natural (...), em um estudo não-experimental não se constrói uma situação, mas se observam situações já existentes, não provocados intencionalmente pelo pesquisador" (p.224 e 225).

Utilizamos uma abordagem de modelo qualitativa, com paradigma interpretativo e método descritivo, pois trabalhamos com o intuito apenas de observar 0 objeto de estudo em seu contexto para um entendimento e melhor compreensão de como acontece o fenômeno em sua linguagem natural com a finalidade de obter uma interpretação e descrição condigna das informações obtidas no decorrer da aplicação da investigação.

A partir desse modelo de investigação, os dados obtidos através da pesquisa terão um diagnóstico que assinala a fidelidade dos fatos bem como a divulgação e apresentação dos resultados alcançados. Com base neste modelo Prodanov; Freitas (2013) corrobora: "Na análise dos dados utilizamos o método qualitativo, que coleta as opiniões e comportamentos de um determinado grupo. A análise ocorreu também de modo descritivo, ou seja, as informações coletadas e a conclusão das mesmas foram registradas de acordo com o resultado da pesquisa. $\mathrm{Na}$ abordagem qualitativa, a pesquisa tem 0 ambiente como fonte direta dos dados. 0 pesquisador mantém contato direto com 0 ambiente e o objeto de estudo em questão, necessitando de um trabalho mais intensivo de campo"(p.51-52).

Como a intenção é apenas descrever sobre os dados coletados, sobre como acontece a inter-relação entre as variáveis temos então uma pesquisa descritiva. Trata-se do método descritivo, onde Prodanov; Freitas, (2013), em seu entendimento retrata que: "Tal pesquisa observa, registra, analisa e ordena dados, sem manipulá-los, isto é, sem interferência do pesquisador. Procura descobrir a frequência com que um fato ocorre, sua natureza, suas características, causas, relações com outros fatos. Assim, para coletar tais dados, utiliza-se de técnicas específicas, dentre as quais se destacam a entrevista, o formulário, o questionário, o teste e a observação" (p. 51-52).

Os dados coletados serão as informações pertinentes a responderem o objetivo da pesquisa e passarão, portanto, por um processo de interpretação para posterior descrição e apresentação do resultado da pesquisa.

\section{1.-Técnica de coleta de dados.}

Para uma maior compreensão das técnicas de coleta de dados, compreendemos que é a forma, estratégia, meio que utilizamos para obter com êxito o resultado da pesquisa, a qual é de fundamental importância para o desenvolvimento do trabalho é através dela que se conhece melhor a realidade do objeto em estudo de forma empírica e contextualizada.

$\mathrm{O}$ instrumento considerado adequado para coletar os dados da pesquisa foi uma lista de comprovação que foi aplicada durante as aulas que ocorreu na sala de Recurso Multifuncional.

Neste momento foram vivenciadas, observadas e registradas a reação do aluno quando desafiado na produção de textos em quadrinhos e leitura das referidas produções.

Participaram da pesquisa 05(cinco) alunos que com déficit cognitivo atendido na Sala de Recurso do Centro de Atendimento Especializado de Boa Vista/RR. Foram utilizados instrumentos para coleta de dados como uma Lista de Observação, contendo 3(três) 
critérios e 17 indicadores. As Observações se deram a partir da realização de aulas na Sala de Recurso Multifuncional.

Foram realizadas 12(doze) aulas no total, cada uma com o objetivo de leitura e produção textual, totalizando 06(seis) planos de aulas de 8horas cada. As aulas foram executados de forma individual e coletiva, com duração de 4 horas cada, tendo em vista a necesidades especifica de cada aluno, como também, a falta de recurso para a dinamização da aula, havia apenas um notebook para realizar as atividades. No momento de execução das atividades, os alunos eram submetidos aos desafios, todos em torno da leitura e posteriormente, da produção de quadrinho.

No total, foram produzidos 06(seis) textos, com historias diferenciadas. Utilizaram para produção dos mesmos, as ferramentas disponibilizadas no software, observando os graus de dificuldades e de manuseio de cada uma.

\section{2.-Analise dos resultados.}

A pesquisa desenvolvida teve como instrumento de investigação uma lista de comprovação com observações em alguns critérios referentes a estrutura, produção textual, leitura e satisfação em relação ao software livre HagáQuê aplicado aos alunos com déficit cognitivo atendidos na Sala de Recurso Multifuncional do Centro de Atendimento Especializado de Boa Vista/RR.

As informações coletadas possibilitaram o acesso a dados relevantes para o esclarecimento da pesquisa, oferecendo uma visão mais ampla sobre o software HagáQuê na produção de textos em quadrinhos com alunos com déficit cognitivo atendidos na Sala de Recurso Multifuncional.

Para coletar os dados que vieram responder a pesquisa, criamos na lista de observação os seguintes critérios: Software Hagaquê- estrutura, produção textual, leitura e satisfação a ser aplicado aos investigados, com alguns indicadores que buscam entender como os alunos se sentem em relação ao software usado para a produção de texto, respondendo assim, o seguinte objetivo específico:

Objetivo 1: Identificar no software livre as possibilidades de construção de quadrinhos a partir de suas ferramentas para alunos com deficiência intelectual.

Categoria de Alunos - Análise da Observação:

Para respondermos ao objetivo 1 elaborou-se o critério de Software HagáQuê-Estrutura, o qual viemos analisar como se dará a estrutura do software livre HagáQuê. Para este critério criamos alguns indicadores para verificar se a estrutura do mesmo corresponde as necessidades de produção textual em quadrinho.

No indicador 01 buscou verificar se: 0 software apresenta banco de imagens com cenários, personagens e objetos. Os resultados obtidos a partir das observações realizadas in loco em Sala de Recurso, foi possível perceber no Software livre HagáQuê a existência de um banco de imagens com cenários e personagens, objetos disponível para interação do aluno. A partir da observação, foi possível perceber a relevância das imagens para a produção textual dos alunos com déficit cognitivo, facilitando sobremaneira a sua escrita, as imagens ajudam na compreensão do contexto, em especial quando identifica-se a relação entre o desenho e a vivencia do aluno. 
Para Moran, Masetto, Bhrens (2013): "Aprendemos pelo prazer, por que gostamos de um assunto, de uma mídia, de uma pessoa. 0 jogo, o ambiente agradável, o estímulo positivo podem facilitar a aprendizagem" (29).

Nessa concordância de significados, entendemos que o banco de imagens com cenários, personagens e objetos presentes no software HágaQuê vem corroborar para a aprendizagem dos alunos no sentindo da produção textual de quadrinho.

No indicador 02 buscou saber se: 0 aluno consegue manusear com facilidade as ferramentas existentes. Dos 05 (cinco) alunos observados 03 (três) conseguem manusear todas as ferramentas sem dificuldades. Enquanto 02(dois) não consegue manusear sem dificuldades as ferramentas existentes no software.

Nota-se com o resultado da observação, que a maioria dos alunos com déficit cognitivo matriculados na SRM do CAE/BV, manusearam com facilidade as ferramentas disponibilizadas no software HagáQuê. Desta forma, compreendemos que a aprendizagem advinda por meio da interatividade, permite ao aluno com déficit cognitivo manusear com segurança as ferramentas existentes no software, facilitando sobremaneira a construção do seu conhecimento. Ainda sobre o uso de recursos, Oliveira (2006) comenta que o software é um meio simbólico e permite: [...] oferecer um tipo de aprendizagem diferente (ou complementar) ao que aparecem em outras situações nas quais não se utiliza o meio informático [...] possui suas vantagens e suas limitações em relação à tarefa que queremos empreender; e cada uma solicita também diferentes maneiras de tratar a informação [...] utilizam de uma maneira peculiar diferentes símbolos (pictórios, linguísticos, numéricos, algébricos, icônicos e muitos outros) (p. 28).

As palavras de Oliveira (2006) evidenciam a complexidade imbricada no processo de ensino e aprendizagem por meio de ferramenta tecnológica. Essas dificuldades se acentuam muitas vezes pela própria condição do aluno, no caso em questão, o déficit cognitivo, em compreender os comandos existentes para manuseio das ferramentas.

Embora os resultados demonstram que no uso do software HagáQuê a maioria dos alunos pesquisados não tiveram dificuldades em manusear as ferramentas, compreendemos que é indispensável nesse contexto o papel do professor como um agente fundamental para administrar e aproveitar as inúmeras interatividades existentes para atender ao aluno.

No indicador 03 procurou saber se: E possível identificar nas estruturas existentes no software a possibilidade de manuseio de cores e posições dos objetos. Dos 05 (cinco) alunos com déficit cognitivo observado, 04 (quatro) conseguiram identificar e manusear as cores e posições dos objetos para criação dos textos em quadrinho. Apenas 01(um) não conseguiu identificar e nem manusear as cores e posições dos objetos.

Diante do contexto observado, foi possível conceber no software HagáQuê uma potencial ferramenta do campo tecnológico, em especial para a produção de texto em quadrinho, trazendo em seu bojo um referencial de elementos que possibilita ao aluno, manuseio de suas ferramentas como cores, deslocamento de objetos, tamanho.

No indicador 04 procurou saber se: Consegue identificar os desenho e relacionar com seus conhecimentos prévios. Dos 05 (cinco) alunos com déficit cognitivo observado, todos conseguiram identificar os desenho e relacionar com seus conhecimentos prévios, com suas realidades.

Com o resultado da observação, foi possível averiguar que o Software HagáQuê apresenta em suas ferramentas um conjunto de imagens que favorece ao aluno fazer a relação do desenho do software com seus conhecimentos prévios. Assim, o aluno constrói sua 
aprendizagem de forma significativa, conforme enfatizado pelo pesquisador norte-americano Joseph David Ausubel (1969) dizia que, quanto mais sabemos, mais aprendemos, ele afirma que o fator isolado mais importante que influencia 0 aprendizado é aquilo que 0 aprendiz já conhece: "A essência do processo de aprendizagem significativa é que as ideias expressas simbolicamente são relacionadas às informações previamente adquiridas pelo aluno através de uma relação não arbitrária e substantiva (não literal)".( p.47)

Para Freire (2002) o computador provocou diferente maneira de os indivíduos se relacionarem com a leitura e a escrita, chama a atenção para o aspecto da ludicidade como possibilidade de trabalho pedagógico utilizando o software educacional, entre os quais cita os editores de histórias em quadrinhos. Desta forma, observamos que a contribuição do autor vem de encontro com a temática pesquisa, o autor pontua que os recursos tecnológicos permitem ao indivíduo colocar a sua linguagem em funcionamento, de mudar as condições de produção do texto, de praticar a reescrita, mostrando que "aprender a escrever significa escolher entre possibilidades, tomar diferentes decisões" (p. 310), mesmo que este apresente déficit cognitivo ou não, a aprendizagem acontece pelos estímulos advindos do próprio software.

O autor Gesueli enfatiza que: Na produção escrita, a imagem é garantia do significado a qual representa, muitas vezes, todo um enunciado [...] a possibilidade de a imagem fazer parte da produção textual do aluno, dada a experiência visual a que está imbricado, sem que necessariamente esta imagem deva ser substituída por palavras escritas.(p.47).

Comungando da fala do autor, compreendemos a relevância das imagens existente nas ferramentas do software HagáQuê para a produção textual como sendo imprescindível para o aluno compreender o sentido dado a sua produção, conseguindo realizar a quebra de barreiras advinda de sua dificuldade em produzir textos, em detrimento ao déficit cognitivo, sendo, portanto, um recurso concreto para facilitar a escrita a partir de uma ideia advinda das imagens exposta no software HagáQuê.

Objetivo 2 -. Propiciar interação entre os alunos e o uso do software HagáQuê para leitura e construção de textos em quadrinhos.

Categoria de Alunos - Análise da Observação

Para respondermos ao objetivo 2 elaborou-se o critério de Produção de Texto, tal critério nos permite averiguar como se dar a produção de textos a partir da utilização do software HagáQuê. Para este critério criamos um indicador que pudesse perceber na produção dos alunos textos com coerência e coesão.

No indicador 08 buscou verificar se: Os textos produzidos pelos alunos imprime coerência e coesão na sua estrutura. Os resultados obtidos a partir das observações realizadas in loco na Sala de Recurso com os alunos com déficit cognitivo, foi possível perceber a partir da produção dos textos dos 05(cinco) alunos observados que 04(quatro) apresentam coerência e coesão na estrutura do texto produzido, apenas 01 aluno não foi possível ver na escrita a coerência e coesão.

Diante dos resultados imprimidos no gráfico, percebemos que existe uma intrínseca relação entre a produção textual dos alunos e o software HagáQuê. Para Vygotsky 1987, há potencialidades e capacidades nas pessoas com déficit cognitivo, mas entende que, para estes desenvolvê-las, devem ser-lhes oferecidas condições materiais e instrumentais adequadas, com isso, deve-se oferecer as tais pessoas uma educação que thes oportunize a apropriação da cultura histórica e socialmente construída, para melhores possibilidades de desenvolvimento. 
Assim, o software HagáQuê estampa em suas estrutura ferramentas de manuseio que facilita o raciocínio dos alunos para que criem suas próprias historias através dos estímulos contidos nas mesmas.Segundo Gros (2003) enfatiza que o jogo: "Para serem utilizados com fins educativos, os jogos precisam ter objetivos de aprendizagem bem definidos e ensinar conteúdos do uso dos usuários, ou então, promover o desenvolvimento de estratégias, ou habilidades importante para ampliar a capacidade cognitiva"( p.8).

Para respondermos ao objetivo 2 elaborou-se o critério de Satisfação.

No indicador 15 buscou verificar se: Envolve os participantes em sua dinâmica. A partir das observações realizadas com visitas in loco na Sala de Recurso Multifuncional com os alunos com déficit cognitivo, foi possível observar que todos os 05(cinco) alunos que participavam da pesquisa, se envolveram com a dinâmica apresentada através da interação com 0 Software HagáQuê, demonstrando satisfação em participar das atividades desafiadas a eles no momento de seu atendimento na SRM.

$04^{\circ}$ (quarto) indicador buscou verificar se "os gestores viabilizam meios para a efetivação do ensino inclusivo às pessoas com deficiência física". Os resultados obtidos revelam que os gestores das escolas $A, B, C$ e $D$, não viabilizam meios para a efetivação do ensino inclusivo às pessoas com deficiência física.

Nas visitas in loco nas escolas supracitadas, não foi constatados nenhum mecanismo que caracterizassem a viabilização de meios para a efetivação do ensino inclusivo às pessoas com deficiência física, contrariando o disposto na Política Nacional de Educação Especial na Perspectiva da Educação inclusiva Brasil( 2008): "Os sistemas de ensino devem organizar as condições de acesso aos espaços, aos recursos pedagógicos e à comunicação que favoreçam a promoção da aprendizagem e a valorização das diferenças, de forma a atender as necessidades educacionais de todos os alunos".(p. 14)

Neste sentido, implica afirmar o notório descaso das escolas $A, B, C$ e D quanto a inclusão dos alunos com deficiência física, configurando uma prática exclusiva e discriminatória, infringindo a Constituição Federal, Brasil, (1988), lei soberana do País.

Objetivo 3 - Analisar textos afim de reconhecer a sua tipologia

Categoria de Alunos - Análise da Observação

Com intuito de responder ao objetivo 3 elaborou-se o critério: Produção de Texto, tal critério nos permite averiguar como se dar a produção de textos a partir da utilização do software HagáQuê. Para este critério criamos indicadores que pudesse perceber na produção dos alunos a identificação da tipologia textual partir das ideias imprimidas no texto.

No indicador 06 buscou verificar se: E de fácil identificação dos tipos de textos produzidos a partir do uso do software. Os resultados obtidos a partir das observações realizadas in loco na Sala de Recurso com os alunos com déficit cognitivo, foi possível perceber a partir da produção dos textos dos 05 (cinco) alunos observados que todas as produções deixam claro o tipo de texto impresso nas ideias dos alunos.

Ao observar a dinâmica do trabalho realizado através do uso do software na SRM, foi possível perceber claramente na intenção dos alunos a predominancia da tipologia de texto de narrativas. Como a proposta era trabalhar quadrinhos, as imagens contidas no software já direcionam o aluno para essa tipologia textual.

No indicador 10 procurou saber: Consegue ler e compreender as produções realizadas com a ajuda do Software. Dos 05(cinco) alunos com déficit cognitivo observados, 04(quatro) conseguem ler e compreender as produções, apenas 01(um) aluno não foi possível compreender sua escrita de forma a entender todo o texto. Embora o aluno apresentassem 
essa dificuldade na leitura e escrita, fez a leitura oralmente de toda a sua produção, sendo possivel perceber a intencionalidade da representação dos desenhos na sua narrativa.

Objetivo 4: Averiguar através de observações direta o uso do software com os alunos com déficit cognitivo suas possíveis contribuições para aprendizagens dos mesmos.

Categoria de Alunos - Análise da Observação

No propósito de responder ao objetivo 4, elaborou-se o critério Leitura, o qual viemos observar a leitura dos alunos com déficit cognitivo a partir do uso do software livre HagáQuê. Para este critério criamos o indicador: Consegue realizar a leitura das imagens.

Os resultados obtidos a partir das observações realizadas in loco na Sala de Recurso Multifuncional com os alunos com déficit cognitivo, foi possivel perceber que todos os alunos observados consegue realizarem a leitura das imagens, portanto, concebemos 0 software HagáQuê como sendo um exime potencial no sentindo de oferecer aos seus usuários, imagens que correspondem com o dia a dia dos alunos, facilitando sobremaneira a leitura e identificação de cada imagem.

No propósito de responder ao objetivo 4, elaborou-se o critério Satisfação, o mesmo se propõe a observar a satisfação dos alunos com déficit cognitivo que são atendidos na Sal de Recursos Multifuncionais do Centro de Atendimento Especialidade de Boa Vista/RR, a partir do uso do software livre HagáQuê. Para tal, criamos alguns indicadores que julgamos serem imprescindíveis na resposta da problemática.

No indicador 12 procurou saber: Expressa gostar do software. 0 resultado da observação realizadas com os alunos com déficit cognitivo atendidos na Sala de Recurso Multifuncional do Centro de Atendimento de Boa Vista/RR foram unanimes, dos 05(cinco) alunos observados, todos comungam da mesma satisfação, consideram que o Software os ajuda na realização das atividades de forma a facilitar seu raciocínio, sobre tudo na produção textual.

No indicador 13 procurou saber: Demonstra motivação e prazer ao criar textos no software. $O$ resultado da observação realizadas com os alunos com déficit cognitivo atendidos na Sala de Recurso Multifuncional do Centro de Atendimento de Boa Vista/RR, demonstrou que dos 05(cinco) alunos observados todos eles apresentaram satisfação e prazer no momento de desenvolverem as atividades usando as ferramentas do software.

No indicador 14 procurou saber: Corresponde aos estímulos advindos das ferramentas do software. O resultado da observação realizadas com os alunos com déficit cognitivo atendidos na Sala de Recurso Multifuncional do Centro de Atendimento de Boa Vista/RR, demonstrou que dos 05(cinco) alunos observados todos eles correspondem aos estímulos advindos do software. Vale ressaltar, que embora os alunos que participaram da pesquisa serem alfabetizados, os ritmos de aprendizagem são diferenciado, conforme as especificidades de cada um.

No indicador 16 procurou saber: Eficaz como ferramenta de produção textual. 0 resultado da observação realizadas com os alunos com déficit cognitivo atendidos na Sala de Recurso Multifuncional do Centro de Atendimento de Boa Vista/RR, demonstrou eficácia ao serem utilizados com os 05(cinco) alunos observados, todos eles conseguiram realizar as atividades proposta a partir do uso do software. 


\section{5.-Conclusão.}

A educação inclusiva é um desafio, que ao ser devidamente enfrentado pelas instituições de ensino, promove a melhoria da qualidade dos estudantes com deficiência. Pois para que os alunos com Déficit Cognitivo possam alcançar a aquisição de sua aprendizagem, sem prejuízos, é necessário um ensino que os abarque, lhes deem essa oportunidade de serem assistidos diante de suas dificuldades e especificidades, exercendo o direito à educação em sua plenitude. Nesse cenário, a informática tem um papel fundamental no desenvolvimento desses alunos.

Atualmente, já se pode afirmar que os indivíduos com déficit intelectual são capazes de realizar processos cognitivos semelhantes aos das crianças que não apresentam esse tipo de déficit, no que se refere ao aprendizado da leitura e da escrita, embora seu ritmo de aprendizagem aconteça de forma mais lenta. Por isso, as estratégias de ensino para esses alunos podem ser as mesmas utilizadas com os demais alunos. Enfatiza-se que no ensino da escrita seja preciso estimular o aluno a se comportar de forma ativa na atribuição de significados para aquilo que se aprende. Para tanto, é preciso que ocorra uma reflexão sobre a maneira pela qual pode ocorrer o encontro da tecnologia com o ensino de língua, respaldado numa teoria consistente capaz de se propor a resolver problemas no processamento textual comum entre os com déficit cognitivo.

Desta forma, o software Livre HagáQuê se apresenta como mediador entre o aluno com déficit cognitivo e sua aprendizagem, sendo a escola a principal responsável no aprimoramento desse ensino, para que esses aluno tenham uma experiência educacional proveitosa.

Diante desses pressupostos, esta pesquisa se propôs analisar o software livre HagáQuê como ferramenta pedagógico para leitura e produção de textos em quadrinho com alunos com déficit cognitivo atendidos na sala de recursos multifuncionais do Centro de Atendimento Especializado de Boa Vista/RR.

A pesquisa foi respaldado em alguns referenciais teóricos de onde foi possível retirar citações diretas e indiretas, que vieram complementar a experiência vivida da autora através das observações realizadas em in loco a partir de uma lista de observação, onde foi possível evidenciar resultados favoráveis sobre 0 uso do software HagáQuê como ferramenta pedagógica na produção de textos em quadrinho com alunos com déficit cognitivo atendidos na Sala de Recurso do Centro Especializado de Boa Vista/RR. As principais análises que compõem esta investigação científica fazem alusão ao seguinte problema: Como o software livre HagáQuê pode ser considerada uma ferramenta pedagógica para leitura e produção textual em quadrinho para os alunos com déficit cognitivo?

As respostas dessa pesquisa contribuíram para a análise dos dados coletados, evidenciando que o o software livre HagáQuê é uma potente ferramenta pedagógica na leitura e produção de textos para alunos com déficit cognitivo.

Foi averiguado no objetivo 01 da pesquisa que tem como incumbência Identificar no software livre as possibilidades de leitura e construção de quadrinhos a partir de suas ferramentas para alunos com déficit cognitivo, confirmou-se que o software observado atende com suas ferramentas em varias possibilidades que favoreça 0 aluno na sua leitura como também, na sua produção textual, desta forma, credita-se no software livre HagáQuê uma potencial ferramenta pedagógica, favorecendo sobremaneira a aprendizagem dos alunos com déficit cognitivo. 
No objetivo 02 da pesquisa que tem como desafio propiciar interação entre os alunos e 0 uso do software HagáQuê para leitura e construção de textos em quadrinhos, foi possível conceber que 0 software pesquisado, apresenta uma gama de ferramenta que notoriamente é disponibilizada aos alunos para uso e manuseio da forma como thes é mediado pelo professor. Permitindo aos alunos ler e produzir textos diferenciados, interagindo com as imagens, cores e escolhas de desenhos, conforme sua criatividade. Ficou evidenciado ainda, que os textos produzidos pelos alunos apresentam coerência e coesão, sendo adequados a leitura por outros leitores.

Conforme 0 objetivo 03 da referida pesquisa: analisar textos afim de reconhecer a sua tipologia, constatou-se que os textos construídos pelos alunos apresentam como principal tipologia, a narração. Os alunos conseguiram realizarem a leitura das imagens de forma que os favorecessem nas suas respectivas produções. Enfatizamos que essas leituras precedem a própria produção, sendo um potencial para que o aluno consiga se identificar com as imagens e ajudar na sua criatividade no momento da construção do texto. concebemos o software HagáQuê como sendo um exime potencial no sentindo de oferecer aos seus usuários, imagens que correspondem com o dia a dia dos alunos, facilitando sobremaneira a leitura e identificação de cada imagem.

Constatou-se no objetivo 04 da pesquisa: averiguar através de observações direta o uso do software com os alunos com déficit cognitivo e suas possíveis contribuições para aprendizagens dos mesmos, que o software comunga com as principais ferramentas pedagógicas utilizadas na aprendizagem dos alunos, em especial, os alunos com déficit cognitivo. Através dos critérios e indicadores propostos para a confirmação do objetivo, foi possível averiguar motivação na leitura e produção textual realizados pelos alunos com déficit cognitivo a partir do uso do software HagáQuê .

Assim, a presente pesquisa, concluiu que os resultados acerca do uso software livre HagáQuê como ferramenta pedagógico para leitura e produção de textos em quadrinho com alunos com déficit cognitivo atendidos na sala de recursos multifuncionais do Centro de Atendimento Especializado de Boa Vista/RR, foram bastante satisfatório, mesmo entendendo que os entraves, como a dificuldade devido ao déficit cognitivo pelos alunos, sejam empecilho para 0 alcance de aprendizagem plena, no entanto, ficou claro na pesquisa que os alunos aprendem de forma significativa que segundo Ausubel(1969), ocorre quando o sujeito se apropria de situação favorecedoras a partir das informações prévia já armazenada em sua estrutura cognitiva, propiciando oportunidade de recepcionar a nova informação, estabelecer relações e elabora-las.

\section{6.-Referências bibliográficas.}

Ausubel, D.P.(1969). Readings in school learming. London: Holt, Rinehart and inston.

Brasil (1994) Declaração de Salamanca e Linha de Ação sobre Necessidades Educativas Especiais. Brasília: Coordenadoria Nacional para Integração da Pessoa Portadora de Deficiência.

Brasil (2008) Política Nacional de Educação Especial na Perspectiva da Educação Inclusiva. Brasília: Secretaria de Educação Especial/MEC. 
Freire, P., y Faundez, A. (2002) Por uma pedagogia da pergunta. 5. ed. Rio de Janeiro: Paz e Terra.

Gesueli, Z.M. (2004). A escrita como fenômeno visual nas práticas discursivas de alunos surdos. In: Lodi, A.C.B., Harrison, K.M.P., Campos, S.R.L. Leitura e escrita no contexto da diversidade. Porto Alegre: Mediação.

Mantoan, M.T., Pietro, R.G., y Arantes,V.A. (Org.). (2006). Inclusão escolar: pontos e contrapontos. São Paulo: Summus.

Raiça, D. (2006). 10 Questões sobre a educação inclusiva da criança com deficiência mental. São Paulo: Avercamp.

Rodrigues, C. (2009). Mente estimulada. Revista Nova Escola, no 223. São Paulo: Abril.

Vygotsky, L.S. (1991). Pensamento e Linguagem. São Paulo: Martins Fontes, 1991.

Vygotsky, L.S. (1986). A formação Social da Mente. São Paulo: Martins ontes.

Sampieri, R.H.C., Carlos, F.L., y Pilar, B. (2008). Metodologia de La Investigación. 4 ed, Mexico: McGrawHill. 